\section{The Coal-Dust Theory}

ThOSE readers of NATURE who have followed the various phases of the coal-dust question will be interested to know that the following resolution was carried at the Conference of Miners, which concluded its sittings in Birmingham yesterday morning :-

"This Conference, believing that recent explosions have demonstrated that coal-dust is sufficient, without the presence of gas, to cause a serious explosion, is of opinion that a clause should be inserted in the new Mines Act, making it illegal to use blasting-powder, or other inflammable substance, in any part of the tram or trolly-way, unless the dust on the top, the bottom, and the sides of such tram or trolly-way has been properly damped or removed, for a distance of fifteen yards on each side of the hole in which the shot is to be fired."

This practical method of dealing with part of the difficulty will doubtless lead to the happiest results, if properly carried out.

The use of dust-tight tubs, or mine-waggons, as a means of preventing the deposition of coal-dust in the first place, and thus avoiding the necessity for so many precautions in dealing with it afterwards, suggested itself to me while I was examining the scene of the explosion in the silkstone-pits at Altofts Colliery. In order to fulfil the condition of being dust-tight, the mine-waggons would require to have no crevices of any kind through which dust could be shaken, and they would require to be so filled that no pieces of coal would roll over their sides on to the floor.

This alternative method, which I propose to discuss at greater length elsewhere, showing practical results as far as they extend, might perhaps meet the case of those mines in which the use of water is objectionable, on account of its disintegrating effect upon the roof or floor.

Cardiff, January I 5

\section{Barnard's Comet at Perihelion}

IN spite of the bad weather and the glare of twilight and moonlight, I have made a good number of observations and drawings of this comet; especially on December 16, I886, the day of its passage at perihelion, and consequently of its shortest distance from the sun (nearly two-thirds of the distance of the earth from the sun).

The head of the comet was a large, brilliant, star-like nucleus, surrounded with a splendid, globular chevelure. From this sprang two tails : the larger, directed towards the North Pole, was straight, or but a little convex to the east (on which side it was also a little thicker), ending in an extremely faint nebulosity nearly $10^{\circ}$ from the head. The smaller tail was much shorter, and directed $50^{\circ}$ to the west of the other. The colour of the comet was a beautiful light blue.

The spectrum of the comet resulted from the ordinary three bands of the hydrocarbons; the green being the strongest, then the yellow, whilst the blue was the faintest. The bands were crossed by the linear spectrum of the nucleus, continuous, but strongly reinforced on the bands, and extended very little beyond the limits of the bands themselves.

Before the passage at perihelion the comet had the same form, but less developed; the spectrum also was the same.

On the morning of December 7 I followed the comet with the ro-inch refractor till twenty-five minutes before sunrise : this proves the great brilliancy of the comet.

A. Riccò

Palermo Observatory, January 9

\section{Magnetic Theory}

MAY I trespass upon your space to ask a questiun which I have never seen proposed, but which is so obvious that it must have occurred to many others int erested in magnetic theory?

In a current field-with closed currents-we have the familiar equations-

$$
\begin{gathered}
F=\iiint \frac{u d x d y d z}{r}, G=\& c ., H=\& \mathrm{c} . \\
\frac{d u}{d v}+\frac{d v}{d y}+\frac{d w}{d z}=0=\frac{d F}{d x}+\frac{d G}{d y}+\frac{d H}{d z}, \\
\nabla^{2} F+4 \pi u=0, \& \mathrm{c} .
\end{gathered}
$$

And if $a, b, c$ are the components of magnetic force-

$$
a=\frac{a^{\prime} G}{d z}-\frac{d H}{d y} \& \mathrm{c} ., \quad 4 \pi u=\frac{d c}{d y}-\frac{d b}{d z} \& c .
$$

In a magnetised mass, $A, B, C$ being components of mag. netisation, if we take

$$
F=\iiint\left\{B \frac{d}{d z}-C \frac{d}{d y}\right\} \frac{d x d y d^{l} z}{r}, \quad G=\& \mathrm{c} ., \quad F=\& \mathrm{c} .
$$

We have at all external points a magnetic force of the components $a, b, c$, where $a=\frac{d G}{d z}-\frac{d H}{d y}$, \&c.

If we introduce the vector whose components per unit volume, $u, v, w$, are $\frac{d B}{d z}-\frac{d C}{d y}, \& c$, where $A, B, C$ are continuous and per unit surface are $n B-m C$ over surfaces where $A, B, C$ pass discontinuously to zero, we get $F=\iiint \frac{u d x d y d z}{r}$, \&c.

$$
\frac{d u}{d x}+\frac{d v}{d y}+\frac{d w}{d z}=0=\frac{d F}{d x}+\frac{d G}{d y}+\frac{d H}{d z},
$$

and all the equations of the current field are reproduced.

Only the components $\alpha, \beta, \gamma$, of the magnetic force at intemal points, being derivable from the potential

$$
V=\iiint \frac{\mathbf{1}}{r}\left(\frac{d A}{d x}+\frac{d B}{d y}+\frac{d C}{d z}\right) d x d y d z
$$

are not identical with $a, b, c$, as they do not satisfy the equations $\frac{d c}{d y}-\frac{d b}{d z}=4 \pi u, \& \mathrm{c}$.

My question is, what is the physical evidence in favour of the existence of $A, B, C$ and $\alpha, \beta, \gamma$ ?

All we know, and can know, about a magnetised mass is derivable from observations of the external field.

Everything, therefore, that we can know is satisfied by expressing the state of the mass in terms of $u, v, w$, and regarding these quantities as the ordinary electric current components. So that $a, b, c$ are components of force everywhere.

My meaning is that if the order of our investigations had been reversed, commencing with current phenomena and so passing on to magnetic, it seems almost certain that we should have attempted to explain the latter in terms of the former.

Doubtless many of the observed facts of induced magnetism would present grave difficulties, but I do not think these difficulties would have driven us to the hypothesis of permanently polarised molecules, or that we should have derived any additional help from such hypothesis.

Berkeswell Rectory, Coventry

\section{Sounding a Crater, Fusion-Points, Pyrometers, and} Seismometers

I HAD expected to see some confirmation of the remarks that form the chief part of the letter on this subject by Dr. H. J. Johnston-Lavis in NATURE of the 3oth ult. (p. 197), but as no one has taken up the matter yet, perhaps you will allow me, as for years the chief assistant of the late Robert Mallet, to say that it is quite true that elaborate apparatus was devised by him and made by different instrument-makers, with a view to obtaining experimental imformation on the whole of the questions and more than those referred to by Dr. H. J. Johnston-Lavis. A preliminary report was presented by him to the British Association in 1863 , in which the scope of his inquiry and nature of apparatus were mentioned, and other reports were written by him which I have not by me now. I am also able to say that the whole of the apparatus remained for years, through Prof. Guiscardi, in the University of Naples, and that Mallet wrote to him as to its disposition for the use of others, should occasion permit, just before his death. W. WORBY BEAUMONT

Norwood Road, S.E.

\section{Folkestone Gault}

Mr. John Griffiths, of Folkestone, the well-known collector of Gault fossils, is without resources, and is permanently disabled by rheumatism, brought on by exposure in his daily labours, which have not only enriched the museums of Europe and the United States, but have formed the groundwork of the investigations into the zones and fossils of the Gault made by myself and fellow-workers-the Rev. Prof. Wiltshire, F.G.S., before my own endeavours, and those of Messrs. F. G. H. Price, F.G.S., and Starkie Gardner, F.G.S., since, Mr. F. G. H. Price, of Messrs. Child's Bank, Temple Bar, W.C., has kindly undertaken to receive subscriptions.

H.M. Geological Survey

C. E. De Rance 